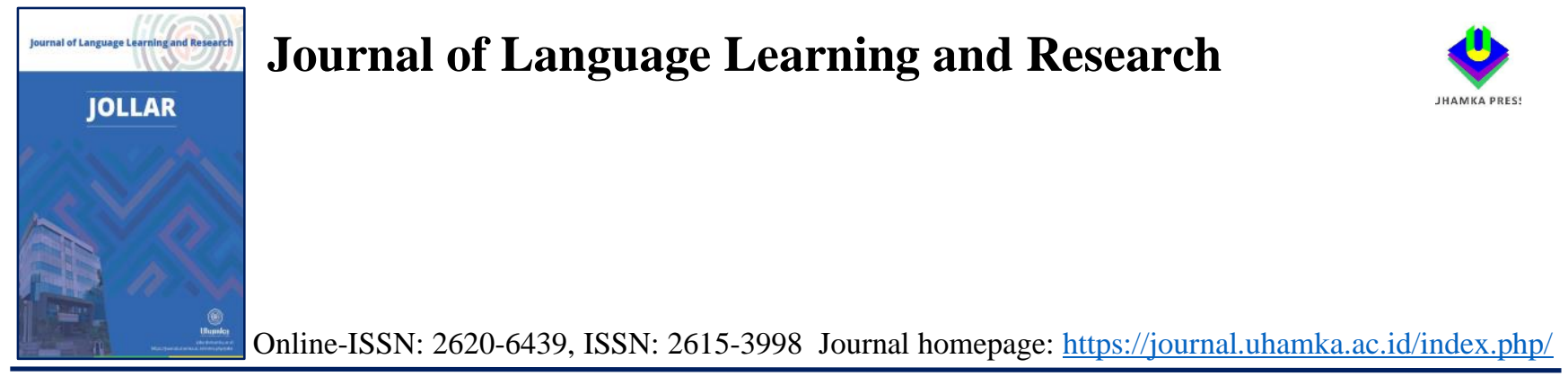

\title{
English Calques in Bangla
}

\section{Sarwar Morshed}

How to cite : Morshed., S., 2019. English Calques in Bangla. Journal of Language Learning and Research. 2(1). 1-11. https://doi.org/10.22236/jollar.v2i1.3491

To link to this article: https://doi.org/10.22236/jollar.v2i1.3491

(C)2021. The Author(s). This open access article

is distributed under a Creative Commons

Attribution (CC BY-SA) 4.0 license.

Published Online on 11 Maret 2020

$\$$ Submit your paper to this journal

View Crossmark data 2 


\title{
English Calques in Bangla
}

\author{
Sarwar Morshed
}

\begin{abstract}
Two hundred years of colonial rule brought the Anglophones in close proximity to the Banglophones. This long time interaction resulted in bilingualism which ultimately paved the way for lexical penetration from English into Bangla. This influx is manifest in the corpus of the Bangla language. Viddyasagar in his Shobdosongroho (1823, Quoted in Musa and Ilyas, 2002:11) compiled a list of 40 English loanwords in Bangla. Within the timespan of nearly two centuries, according to Musa and Ilyas (2002), the lexical loan got multiplied by almost 88 times. Side by side borrowing direct anglicisms, Bangla has also borrowed hosts of indirect loans in the form of 'calques' or 'translation loans' from English. The prime focus of this paper is to trace the mechanisms by which Bangla produces calques from English sources. The results of this study reveal that Bangla has four types of calques single-word, multi-word, phrasal, and acronymic. While our data mostly conform to the global typology of calques, interestingly enough, Bangla has constructed a special class of calques which we have dubbed as 'Acronymic calques'. Translation acronyms are yet to be registered in the typology of calques. This curious calque type attested by our data can be added to the global typology of loan translations.
\end{abstract}

Corresponding author: sarwarmorshed@hotmail.com 


\section{INTRODUCTION}

As different authors have offered different definitions of calques, let us first have a look at the dictionary definitions of the term. According to the American Heritage College Dictionary, a calque is a 'form of borrowing from one language to another whereby the semantic components of a given term are literally translated into their equivalents in the borrowing language.'(1997:795). Trask (1997) in his Student's Dictionary of Language and Linguistics offers the following definition of calques

- $\quad$ A calque is defined as a word or phrase in another language as a model and translating it piece by piece. For example, the ancient Greek word 'sympathy' or 'compassion' was 'sympathia' formed from 'syn' (with) and 'pathia' (suffering). The Romans calqued this Greek word into Latin as 'compassion' from 'con' (with) and 'passion' (suffering). Pei (1978) in his Glossary of Linguistic Terminology defines calques as a translation loanword, the translated imitation of a special meaning.

The above definitions culled from the dictionaries contain the following features of calques:

- They are special kind of borrowings

- They are literal translations of foreignisms into a recipient language

- The translations can be bit-by-bit, root-by-root or word- for-word

From the above discussion, we can say that a calque is special kind of loanword. The word 'calque' is of French origin, literally meaning 'copy or imitation'. Etymologically speaking, calques are literal translations of foreign words or expressions into a borrowing language. Elements from the donor language are translated verbatim into the recipient language. The translation can be word- forword or root- for-root. Calques also go by the name of 'loan translations'.

Common examples of calques in English include 'loanword' (from German Lehnwort), 'superman' (From German ubermensch), 'flea market' (from French marche aux puces), 'tracing paper' (from French Papier calque). It goes without saying ( $\mathrm{Ca}$ va sans dire) that French is the source language for many calques popularly used in English. Some popularly used examples of English calques in Bangla are -

Ulango sottyo - Naked truth

Chhuthir mejaj - Holiday mood

Baiyurodhi - Air-tight

Punormilon - Reunion. 


\section{Theoretical Background}

There are some controversies regarding the status of calques as loanwords. Though there is a common tendency to treat calques as loanwords, researchers have drawn some subtle distinctions between the two. While loanwords are full borrowings, calques are considered to be semi-borrowings. While loanwords are morpho- syntactically borrowed or copied and transferred to the receiving language, a different process takes place in case of calques. Calque production also entails foreign words or phrases but equivalents of the foreignisms are sourced from the target language. Trask's (1997) view is in good tune with this observation. According to him, calques are constructed from the donor language without borrowing any words directly. To put it in simple terms, we can say that in the formation of calques, foreignisms provide the essence while the target language supplies the building blocks. As a calque is the semantic transfer of a foreignism without the morpho-syntactic component, it is treated as semi-borrowing. Calques are, in essence, semantic vehicles between two linguistic systems or cultures.

In loanword literature, calques have been categorized as indirect loans. The following illustration shows the position of these semi-borrowings among loanwords

Researchers could not reach a rigid consensus in their attempt to typologize calques. Smead and Clegg (1996) and Otheyguy and Garcia (1988) have offered the following classification of calques

- Word calques

- Phrasal calques

Apart from this basic classification, further typologization has been attempted by Silva - Corvalan (1995) -

- Single-word calques

- Multiple-word calques

- Multiple-word calques of bound collocations, idioms and proverbs

- Lexico-syntactic calques

Many other researchers have offered their own classifications of calques from their own viewpoints. The following is the simplest typology of calques generally agreed upon by researchers as it bears basic similarity to most of the classifications -

- Single-word calques

- Multiple-word calques

- Phrasal calques 


\section{Rationale of the study}

Even though calques or loan translations are part of foreignisms, despite the abundance of works on English lexical loans in Bangla, research on English calques in Bangla is very scanty. A few researchers like Chakrabarti (1953), Morshed (2009) and Chaki (2010) have discussed the presence of English calques in Bangla in a passing manner. Calque formation in general and English-based calque construction in particular has not received the treatment at the hands of our researchers that it deserves. This study aims to fill the void in this regard.

\section{Literature Review}

Many researches have been conducted on the presence of calques in English. Even though English has constructed many calques basing on foreignisms from German, Spanish, Latin etc. most of the calques in English are of French origin.

Research literature is replete with works on calque production in English visa-vis other European languages. Many significant studies have been conducted on English-Spanish, English-French, English-German calques. Among them the notable studies are Silva-Corvalan (1995), Otheyguy, Garcia \& Fernandez (1989).

Even though many lexicographic researches have been done on the relationship between Bangla and English, no full-length research has been done on English calques in Bangla. Among the researchers who have attempted to discuss English calques in Bangla include Chintaharan (1953), Morshed (2009) and Chaki (2010).

Chakrabarti (1953) discussed on the negative impact of English calques on Bangla. To shed light on his point, he compiled some popularly used calques and claimed that those calques if overused might render Bangla unintelligible to the average native speakers of the language.

Chaki (2010) has made a catalogue of English calques frequently used in Bangla. In comparison with the previous work, Chaki's (2010) work encompasses wider domains from where the examples are culled. But he does not offer any serious discussion on the calquing process.

Morshed (2009) has made a brief catalogue of English calques in Bangla. The paper has a small section containing an assortment of English calques in Bangla. It, however, does not shed light on the calque construction mechanisms employed by the language. Neither does it attempt to taxonomize the English-based calques. As the main focus of the paper is not calquing, English translation loans have been discussed in a passing manner. 


\section{Materials and Methods}

Mixed method materials have been used in conducting this exploratory study. As there is a dearth of research materials on the topic under study, the paper writer has made use of his native speaking status for data collection. Weinreich (1963) introduced researcher's observation as an authentic source of data. The most authentic data, according to him, can be collected through observation of a keen researcher. To make good for the paucity of materials on English loan translations, the researcher has collected samples of calques from diverse sources.

Apart from the use of researcher's observation, some research materials, anthologies of articles and literary texts have been used for data collection. Last but not the least, lexicographic books and research materials have also supplied an important segment of data for this paper. These data feeders have been duly acknowledged in their proper places and in the reference section.

The collected samples of English-based calques have been appended to this paper. The section titled Appendices is comprised of six sub-sections.

\section{Discussion}

The appendices are composed of diachronic samples of calques used in Bangla. In terms of time span, they range from the times of Tagore to till date. Let us begin our discussion following the reverse chronological frame i.e. discussing the recent examples first.

Appendices $1 \& 2$ are extracts from Chaki (2010). Appendix 1 contains some clichéd calques borrowed from English - Chiruni tallashi (Combing operation), Naljataka (Test tube baby), Uralpul (Fly-over), School-chhut (Drop out), Sabuj biplab (Green revolution), Sabuj sangket (Green signal), Mukta viswaviddyalaya (Open University), Teleuthpath (Teleteasing). All these calques are literal translations of their English counterparts excepting the last one where 'tele' has been retained and wedded to Bangla 'uthpath' to form 'Teleuthpath'. As Bangla is a pluricentric language, some of the calques quoted above have their variants in Bangladeshi Bangla. For example, 'Fly-over' has been calqued as 'Ural sethu' 'Drop out' as 'Jhorey pora shikkharthhi', and 'Open University' as 'Unmuktho viswavidyalaya'. It is worth noting that the Bangladeshi examples are pure wordfor-word translations of their English equivalents while the examples of West Bengal (India) Bangla reemploy some English words $($ Uralpool $=$ Fly-over, School chhut = Drop out, both the words in bold fonts are transliterated English loanwords, 'Pool' and 'School', respectively) to construct calques. The mass media, especially the newspapers, have played an important role in popularizing these loan- translations among the speakers of Bangla. 
Appendix 2 which is also an extract from Chaki (2010:17) is an assortment of idiomatic expressions borrowed into Bangla in the form of calques: Amra ruopoar chamuch mukhey niye jonmai, kodal ke kodal bolte didha korina, kancher ghorey bas koreo dhil chhuri. The idiomatic expressions in bold fonts are literal translation of 'To be born with a silver spoon in the mouth', 'To call a spade a spade' and 'To pelt stones from a glass house'.

Now let us have a glimpse at Appendix 3:

Bhubangaoer (Global village) basindara olondas sahosey (Dutch courage) farasi chhuti (French leave) niye pronoy dibas (Valentine's Day) palan korchhey. Esob Romeo Julietder chiruni tallashi (Combing operation) korey ozone phuto (Ozone hole) theke holeo dhara hobey.

[Trans: The inhabitants of the global village are celebrating Valentine's Day with Dutch courage by taking French leave. These Romeo and Juliets will be traced even if they hide in the Ozone hole by conducting a combing operation]. This is an interesting example of the insertion and appropriation of English idiomatic expressions into the fabric of Bangla syntax.

Appendix 4 is composed of some terminological calques related with the publishing industry.

Appendix 5 is a collection of some calques constructed by Tagore and appended to his Shobdotatta. The brief catalogue contains his popular calques like 'Mahajagotik rashmi' (Cosmic ray), 'Protibedan'(Report), 'Pratibarto kria' (Reflex action) etc. These translationational coinages from the virtuoso have got popular currency in Bangla. But some claques like 'Lal ujani alo' (infra-red light) have not got popular acceptance and hence have almost sunk into oblivion.

Appendix 6 registers the presence of a special kind of calques in Bangla translation acronyms. Morshed (2009) lists some translation acronyms very frequently used in Bangla:

VAT (Value Added Tax) - MuSaK (Mullyo Sangjojan Kar). Bangla word 'Musak' is modelled on the English 'VAT'. Some other Bangla words formed following the English acronymization process are 'JaS' (Jati Sangha - The United Nations), SaS (Sahajyo Sangstha - Charitable organization), 'KaBiKha (Kajer Binimoye Khadyyo - Food for Work) etc.

\section{Findings}

From the corpora incorporated into this paper in the form of appendices, we can discover some common patterns of calque construction in Bangla. It is visible that Bangla has single-word loan translations from English. For example, 'Protibedan' (Report), 'Kendranug' (centripetal), 'Kendratig'(Centrifugal) etc. [Appendix 5]. Some more popular examples of this category include, 'Badhito' (Obliged), 'Anugrihito' (indebted) etc. 
Another noticeable pattern is multi-word calquing - 'Naljataka' (Test tube baby), 'Uralpool' (Fly-over), 'School-chhut' (Drop out), 'Sabuj biplab' (Green revolution)

, 'Sabuj sanket' (Green signal) [Appendix 1]; 'Half-title page'- 'Ardha-akhya patra' (Half-title page), 'Akhya patra' (Title page) [Appendix 3]. Some other examples of this type are - 'Patal rail' (Tube train), 'Gajadanta minar' (Ivory tower), 'Chhdabeshi naach' (Fancy ball, translated by Tagore, 2013:17), 'Kandano gas' (Tear gas) etc. We can draw the inference from the appendices that multi- word calques comprise the bulk of English loan translations in Bangla.

Another category of English-based calques in Bangla the use of which has been attested by our appendices is known as 'Phrasal calques'. Some English phrases and idiomatic expressions are translated into Bangla -

Amra rupor chamuch mukhey niye jonmai (To be born with a silver spoon in the mouth), Kodalke kodal bolte (To call a spade a spade) didha korina, Kancher ghorey bas koreo dhil chhuri (To pelt stones from a glass house). Some other examples of phrasal calques are - Ghorar samne gari (To put the cart before the horse), Kono pathoroi ultathe baki na rakha (To leave no stone unturned), Oronney rodon kora (To cry in the wilderness), Kumbhirasru (crocodile tears) etc. These idiomatic expressions have contributed to the beauty of the Bangla language. In addition to beauty, they have also significantly added to the expressive power of the Bangla tongue. But overuse of the phrasal calques, Chakrabarti (1953) rightly thinks, can make the language incomprehensible to Bangla speakers who do not have sound command over the English language.

The last category of calques [Appendix 6] belongs to a special kind of semiborrowings which can be dubbed as 'Translation acronyms'. These are translated acronyms modelled on the English acronyms. One recent example of translation acronym much in use in Bangla is DuDaK (Durniti Daman Commission - AntiCorruption Commission).

If we attempt at typologizing English calques in Bangla basing on our appendices, we can trace four types of loan translations in Bangla - Single word calque, Multi- word calque, Phrasal calque and Acronymic calque. Among the four types, our data confirm, the second category i.e. Multi-word calque is the most frequently and popularly used English-based calque in Bangla.

\section{Limitations and implications of the study}

The present study is not an exhaustive one on English calquing in Bangla and hence it suffers from a number of shortcomings very typical of this type of study. The data-set employed here for the typologization of English loan translations is very limited and hence inferences based on the appended corpora is not final. Extension and diversification of data in future studies will be helpful in testing the validity of the results of this small-scale study. Moreover, large-scale investigation on this hitherto unexplored topic is expected to contribute to the global data-base on calque typology. 


\section{English loan translations in Bangla: Boon or Bane?}

According to Morshed (2009:109), 'English translation loans in Bangla have grown exponentially'. They seem to be omnipresent in our domains of life. English calques have contributed to the enrichment of the Bangla language through their glorious and productive presence in the government, administration, literature, IT, academia and culture. They have been instrumental in creating new lexemes and expressions in Bangla utilizing its internal resources. Let us think of these recently created calques in Bangla: Sonali karmardan (Golden handshake), Holud sangbadikota (Yellow journalism), Ontarjal (Internet), Somoyrekha (Timeline), Khudey barta (SMS), Tottya mahasarani (Information super highway), Chatjaldi khabar (Fast food), Betar sarathi (RJ), Anon muillo (Face value), Khudratikhudro projukti (Nano technology), Jhatiti mudran (Rush print) etc. These loan translations have widened the semantic horizon of Bangla and have substantially added to the expressive plasticity of our tongue. But we should not be oblivious of the danger of too much calquing. Excessive reliance on calque construction might result in the emergence of, what Chakrabarti (1953: 46) dubbed as, 'Sahebi Bangla' (Anglicized Bangla). According to him, 'Though English elements in Bangla do not deprive it of its grace, they render the language incomprehensible to the masses'. (Translated by the paper writer)

Calques, apart from adding incomprehensibility to Bangla, can also rob the recipient tongue of its native flavor. Too much calquing can deBanglicize Bangla (in terms of style, lexis and syntax). Bankim Chandra rightly says about his own writings - 'Even today, to my utter astonishment, I find that my written Bengali is not proper Bengali. Very often, I notice that whatever I write in Bengali is direct translation from English. (Quoted in Biswas, 1998:32. The quote is translated from Bangla by the researcher)

\section{Conclusion}

English calques in Bangla, like direct loanwords, are pervasive. They are used in the government (Golden handshake - Sonali karamardan), in literature (Handshake)

Hat naranari ; Tagore, 2016: 19), in popular culture and entertainment industry (Cat-walk - Biral hantan, Superstar - Mahataroka), in academic disciplines (Language Acquisition Device - Bhasa arjan jantra, Portmanteau words - Mundumal shobdo, Globalization - Golokayan ) and of course in many domains of day to day life (Chain smoker - Shikal dhumpaii, Serial killer - Kramik khuni, Summit Shirsha boithhak, Skycraper - Gaganchumbi bhaban).

The data that have been used in the preparation of this paper conforms to the basic typology of calques proposed by the linguists. However, we notice an additional class of calques in Bangla which is outside the ken of generally accepted calque typology. This distinct but hitherto untraced or neglected calque type has been dubbed as 'Translation Acronyms' in this paper. 


\section{References}

American Heritage College Dictionary. (1997). Boston: Houghton Miffin Company.

Biswas, N. (1998). Prosongo Bangla Bhasa. Dhaka: Annanya.

Bonnerjee, G.L. (1968). Dictionary of Foreign Words in Bengali. Kolkata: Kolkata University, Chaki, J. 2010. Bagarthakouthuki. Kolkata: Ananda.

Chakrabarti, S.C. (1953). Bhasa Sahittyo O Songskriti. Kolkata: Orient Book Company.

Chatterjee, S.K. (1926). Origin and Development of Bengali Language. Kolkata: University of Kolkata.

Morshed, S. (2009). English Elements in Bangla Lexis. In A. Sen (Ed.) Premier Critical Perspectives. Chittagong: PU, pp. 102-116.

Musa, M. and Ilyas, M. (2002). Banglai Procholito Ingrezi Shobder Obhidhan. Dhaka: Mouli.

Tagore, R. (2016). Chhinnapatra. Dhaka: The Sky Publishers.

Tagore, R. (2013). Europe Probashir Patra. Dhaka:

Kathaprakash. Tagore, R. (2000). Shabdatatta. Dhaka:

Suchipatra.

Pei, M. (1978). Glossary of Linguistic Terminology. New York: Anchor Books.

Smead, R., Clegg, H. (1996). English Calques in Chicano Spanish. In A. Roca \& J. Jensen (Eds.) Spanish in Contact: Issues in Bilingualism (pp. 123129). Somerville: Cascadilla Press.

Otheyguy, R. \& Garcia, O. (1988). Diffusions of lexical innovations in the Spanish of Cuban-Americans. In J. Orstein, D., Bixler-Marquez (Eds.), Research issues and problems in United States Spanish (pp. 203-241). Texas: Pan American University.

Otheyguy, R., Garcia, O., \& Fernandez, M.(1989). Transferring, switching and modelling in West New York Spanish: An Intergenerational Study. Journal of the Sociology of Language, 79, 41-52.

Sarkar, S. (2012). Okaran Byakaran. Dhaka: Shovaprokash.

Silva-Corvalan, S. (1995). Lexico-syntactic modelling across the bilingual continuum. In Fisiak, J. (Ed.) Trends in Linguistics, studies and monogrphs 81: Linguistic change under contact conditions. Pp. 253-270. Berlin: Walter de Gruyter \& Co.

Trask, R.L. (1997). A student's dictionary of language and linguistics. New York: St. Martin's Press Inc. 
Weinreich, U. (1963). Languages in contact: findings and problems. The Hague: Mouton.

\section{Appendices}

The following extracts, originally written in Bangla, has been transliterated by the researcher.

1. Amader Bangla shobder bank balance emnitey pushtha. Tarjoma theke joma shobder onkotao chakrabridhhi harey barchhey. Ami Engrezi thheke tarjomar kothai bolchhi. Ar eisab chatjaldi jhan chakchak shodomudragulo prodhanato songbadjogoteri dan. 'Chiruni tallasitey prochur astrashastra paoa gelo.' Combing or combing operationer ashcharja tarjoma. Naljataka $<$ Test tube baby, Uralpul < Fly-over, Schoolchhut <Drop out, Sabuj biplab $<$ Green revolution, Sabuj sangket < Green signal, Mukto viswavidyalaya < Open university, Teleuthpath < Teleteasing ittiyadi shabda harhamesha toiri hochchhey. (Chaki, 2010: 16)

2. Shobder moto engrezi bagbidhi ba prabachankeo amra atmasath kore niyechhi. Amra rupor chamuch mukhey niye jonmai, kodalke kodal bolte didha korina, kancher ghorey boseo dhil chhuri.

(Chaki, 2010: 17)

3. Bhubanganger basindara olondas sahosey farasi chhuti niye pranay dibas palan karchhey. Esob Romeo Julietder chiruni tallasi korey ozone phuto thheke holeo dhara hobey.

(Morshed, 2016: 05)

4. Flyleaf - Pustani

Spine - Put

Half title page - Ardhaakhyapatra

Ttile page - Akhya patra

Recto - Dundiker pristhha

Verso - Bumdiker pristhha

Copyright - Swattha

Epigraph - Aptapatra

(Sarkar, 2012: 73-75) 
5. Centripetal - Kendranug

Centrifugal - Kendratig

Cosmic Ray - Maha jagotik rashmi

Infra-red light - Lal ujani alo Reflex

action - Pratibarti kriya Report -

Pratibedan

Custom House - Masulkhana

(Tagore, 2000:360-363)

6. VAT (Value Added Tax) - MuSaK (Muillya Sangjojan Kar)

EC (Election Commission) - NiC (Nirbachan Commission)

UN (United Nations) - JaS (Jati Sangha)

(Morshed, 2009: 112) 